\title{
Wave-current induced erosion of cohesive riverbanks in northern Manitoba, Canada
}

\author{
NAVID KIMIAGHALAM ${ }^{1}$, SHAWN CLARK ${ }^{1}$, HABIB AHMARI ${ }^{2}$ \& JOEL HUNT ${ }^{2}$ \\ 1 University of Manitoba, Winnipeg, Manitoba, Canada \\ kimiaghn@myumanitoba.ca \\ 2 Manitoba Hydro, Winnipeg, Manitoba, Canada
}

\begin{abstract}
The field of cohesive soil erosion is still not fully understood, in large part due to the many soil parameters that affect cohesive soil erodibility. This study is focused on two channels, 2-Mile and 8-Mile channels in northern Manitoba, Canada, that were built to connect Lake Winnipeg with Playgreen Lake and Playgreen Lake with Kiskikittogisu Lake, respectively. The banks of the channels consist of clay rich soils and alluvial deposits of layered clay, silts and sands. The study of erosion at the sites is further complicated because the flow-induced erosion is combined with the effects of significant wave action due to the large fetch length on the adjacent lakes, particularly Lake Winnipeg that is the seventh largest lake in North America. The study included three main components: field measurements, laboratory experiments and numerical modelling. Field measurements consisted of soil sampling from the banks and bed of the channels, current measurements and water sampling. Grab soil samples were used to measure the essential physical and electrochemical properties of the riverbanks, and standard ASTM Shelby tube samples were used to estimate the critical shear stress and erodibility of the soil samples using an erosion measurement device (EMD). Water samples were taken to estimate the sediment concentration profile and also to monitor changes in sediment concentration along the channels over time. An Acoustic Doppler Current Profiler (ADCP) was used to collect bathymetry and current data, and two water level gauges have been installed to record water levels at the entrance and outlet of the channels. The MIKE 21 NSW model was used to simulate waves using historical winds and measured bathymetry of the channels and lakes. Finally, results from the wave numerical model, laboratory tests and current measurement were used to estimate the effect of each component on erodibility of the cohesive banks.
\end{abstract}

Key words riverbank erosion; cohesive soil; wave current; erosion modelling; MIKE21

\section{INTRODUCTION}

Breaking waves can have a significant effect on longshore sediment transport and also increase the total applied shear stress close to shorelines (Farhadzadeh et al., 2012). Generally in natural rivers, waves are not significant due to the short fetch length and limited river width but may become significant in navigation channels and also short channels that are built to connect lakes. Therefore, wave conditions in connection channels may be governed by wave conditions in surrounding lakes. Two lake connection channels, the 2-Mile and 8-Mile channels in northern Manitoba, were investigated for erosion. These channels were built to regulate water between three lakes. The study of erosion in these channels is complicated since flow-induced erosion is combined with the effect of significant wave action due to the large fetch length on the adjacent lakes, particularly the effect of waves generated in Lake Winnipeg which is the seventh largest lake in North America. During a site visit in August 2013, erosion and longshore sediment transport was observed in 2-Mile channel due to waves coming from Lake Winnipeg when flow in the channel was not high.

Generally, two major factors generate waves in rivers and channels: wind and boat wakes, but the nature of these two types of wave is different. A primary difference between boat waves and wind waves is the wave period. For example, in the lower reaches of the Swan River, boat wave periods are four times higher than wind waves. The measured boat wave and wind wave periods were up to 8 seconds and 2 seconds, respectively (Gourlay, 2010). Gourlay (2011) compared wind waves and boat waves and presented three effects of wave periods on erosion of riverbanks: (a) for the same wave height, water particle movement due to long-period waves is felt deeper and causes larger water particle velocity; (b) increasing wave period shifts the type of breaking wave from spilling to powerful plunging; and (c) behaviour of riverbank vegetation will be different in these two kinds of waves. Gaskin et al. (2003) studied erosion of cohesive riverbanks of the St Lawrence River in Montreal, Canada. They took undisturbed samples from the riverbank and 
experimentally investigated the effects of current and waves on erosion of these samples. They found that flow is not high enough to cause erosion, and in this area waves are the dominant eroding agent. Also, they found that boat surges have higher erosive power than wind waves. They hypothesized that the interaction of waves, weathering (drying and wetting), and removal of vegetation are the main causes of riverbank erosion in their study reach.

The present study included three main components: field measurements, laboratory experiments and numerical modelling. Field measurements consisted of soil sampling from the banks and bed of the 2-Mile and 8-Mile channels, current measurements and water sampling. Grab soil samples were used to measure the essential physical and electrochemical properties of the riverbanks, and standard ASTM Shelby tube samples were used to estimate the critical shear stress and erodibility of the soil samples using an erosion measurement device (EMD). Water samples were taken to estimate the suspended sediment concentration profile and also to monitor changes in sediment concentration along the channels and with time. An Acoustic Doppler Current Profiler (ADCP) was used to collect bathymetry and current data, and two water level gauges have been installed to record water levels at the entrance and outlet of the channels. The MIKE 21 NSW model was used to simulate waves using historical winds and measured bathymetry of the channels and lakes. Finally, results from the wave numerical model, laboratory tests and current measurement were used to understand the effect of each component on erodibility of the cohesive banks in the study reaches.

\section{STUDY REACH AND FIELD MEASUREMENTS}

To study the erosion of the 2-Mile and 8-Mile channel banks, ten sites were chosen along the channels. ASTM standard Shelby tubes with $76.2 \mathrm{~mm}$ external diameter were used to take undisturbed samples. Figure 1 shows the sampling locations in the 8-Mile and 2-Mile channels and Fig. 2 shows some typical samples that were taken from these sites. Using undisturbed samples is crucial for such studies, especially when studying cohesive sediment which is very sensitive to the natural soil structure. To understand the effect of applied shear stress on the soil samples without any effect of weathering, the samples were collected in August 2013 at locations near the water surface that have recently been exposed to the atmosphere because of a declining water level in the channels. To maintain their original water content, the samples were sealed and kept in a refrigerator at the geotechnical laboratory of the University of Manitoba.

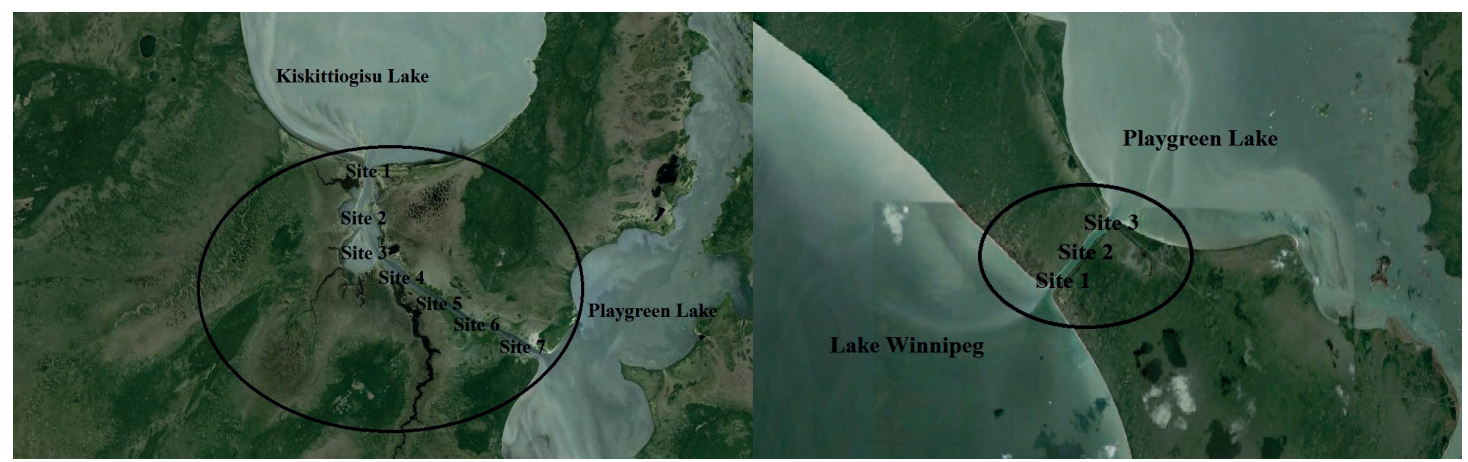

(a)

(b)

Fig. 1 (a) 8-Mile channel sampling sites; (b) 2-Mile channel sampling sites.

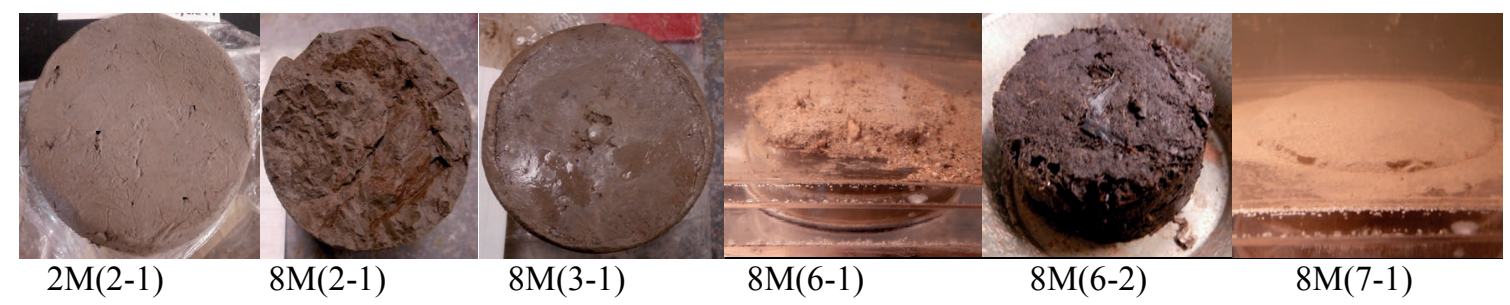

Fig. 2 Soil samples from 2-Mile channel (2M) and 8-Mile channel (8M). 
The study reach was surveyed using a River Surveyor with hydroboard system (Fig. 3). The River Surveyor is an ADCP with real-time kinematics and a GPS system which has a low frequency vertical beam for precise bathymetry surveying. The procedure was to ride the boat along the channels to collect bathymetric data and record discharges.

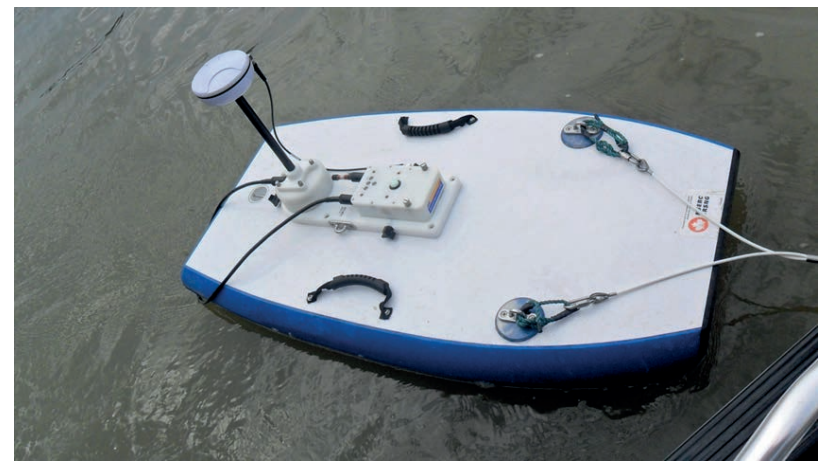

Fig. 3 M9 ADCP River Surveyor from the University of Manitoba (Kimiaghalam et al., 2013).

\section{SOIL TESTING}

Several soil tests were performed to determine the primary properties of the cohesive soil samples: grain size distribution test (ASTM D422), specific gravity of fine soils test (ASTM D854), plasticity index test (ASTM D4318), organic content of soils test (ASTM D2974), electric conductivity (EC) test (Miller \& Curtin, 2006), cation exchange capacity (CEC) test (Hendershot et al., 2006, chapter 18), and sodium adsorption ratio (SAR) test were performed to understand the physical and electrochemical behaviour of these cohesive soil samples. Also, a direct shear test was performed to obtain mechanical properties of the samples. An EMD that has been constructed by the geotechnical group of the University of Manitoba, similar to the device presented by Briaud et al. (2000), was used to estimate the critical shear stress of erosion and also erosion rate. The device comprises a main flume, a water tank, a pump, a recirculation pipe, and an ultrasonic velocimeter. Figure 4 shows the device which works as a conduit thus equation (1) was used to calculate critical bed shear stresses:

$$
\tau=\frac{1}{8} \rho f V^{2}
$$

where $\tau\left(\mathrm{N} / \mathrm{m}^{2}\right) \tau$ is the applied shear stress, $\rho\left(\mathrm{kg} / \mathrm{m}^{3}\right)$ is the water density, $f(-)$ is the friction factor obtained from the Moody diagram, and $V(\mathrm{~m} / \mathrm{s})$ is the mean flow velocity in the conduit.

The erosion function was estimated based on the observations from the experiments and also using the linear definition of erosion rate by Partheniades (1965):

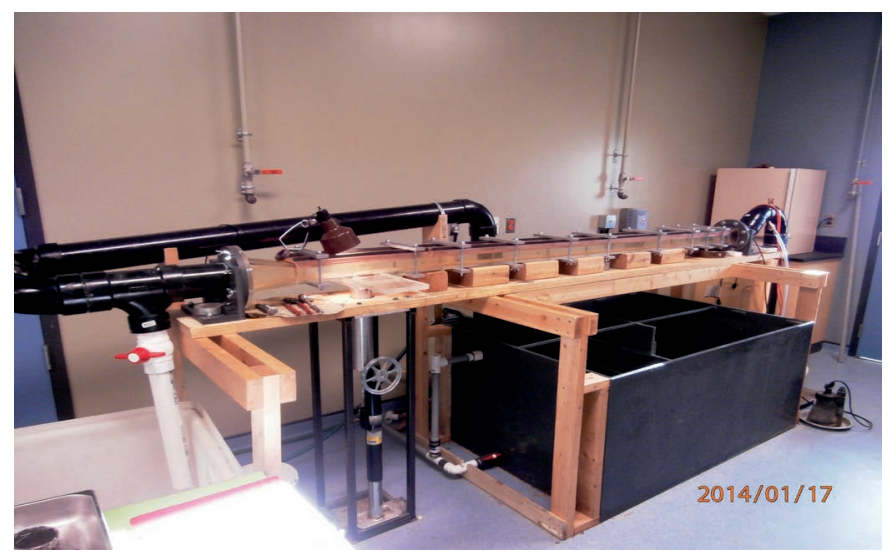

Fig. 4 Erosion measurement device. 


$$
E=M\left(\tau_{a}-\tau_{c}\right)
$$

where $E$ is the erosion rate function, $\tau_{c}$ is the critical shear stress of erosion, $\tau_{a}$ is the applied shear stress and $M$ is a material dependent coefficient.

\section{NUMERICAL MODELLING}

MIKE 21 NSW was used to simulate near shore waves in the 2-Mile and 8-Mile channels. Since these channels are not used heavily for navigation purposes, only wind waves were simulated. The modelling included four main steps: (a) creating bathymetry of the channels and the adjacent lakes based on bathymetry files obtained from ADCP measurements; (b) defining initial and boundary conditions. In this study significant wave height $\left(H_{m 0}\right)$, mean wave period $\left(T_{m}\right)$, mean wave direction $(M W D)$, directional spreading index $(n)$, and maximum deviation from $M W D$ $(M D W D)$ were boundary condition parameters. Boundary condition values were obtained from Manitoba Hydro reports. For 2-Mile channel, data from waves in Lake Winnipeg were used as a constant boundary $\left(H_{m 0}=1.07 \mathrm{~m}, T_{m}=3 \mathrm{sec}, M W D=190^{\circ}, n=5\right.$, and $\left.M D W D=30^{\circ}\right)$ and for 8-mile channel boundary values were $\left(H_{m 0}=0.50 \mathrm{~m}, T_{m}=3 \mathrm{sec}, M W D=190^{\circ}, n=5\right.$, and $M D W D=30^{\circ}$ ); (c) defining the model parameters. In this study, wind data from the Norway House Environmental Canada gauge close to the sites was used. The maximum wind data in June and July were used because the maximum flow usually occurs in these months; (d) calibration was done based on the actual available data and changing the initial values. MIKE $21 \mathrm{NSW}$ is based on the approach proposed by Holthuijsen et al. (1989). The main outputs of the model were wave height, period and direction which were used to estimate shear stresses due to the wind waves.

After calculating essential wave parameters, the MIKE 21 FM MT module was used to model the channel hydrodynamics and calculate bed shear stresses. The modelling procedure was: (a) create a mesh for the channels using available bathymetric data; (b) define the boundary conditions for entrance and exit of the channels based on available flow data. The initial condition for water level in the channel was defined as the average water level in the exit and entrance of the channels; (c) wave data from MIKE NSW was entered into the MT module as well as the bed roughness. Roughness from the EMD test results and Moody diagram was used as bed roughness for this module (around 0.018); (d) calibration was done by changing the Manning number of the channel bed. The main output of this model was shear stresses along the channels. Equation (3) is used in the MIKE 21 FM MT module to calculate the total applied shear stresses (DHI, 2012):

$$
\tau_{b}=\frac{1}{2} \rho f_{W}\left(U_{b}^{2}+U_{c}^{2}+2 U_{b} U_{c} \cos \alpha\right)
$$

where $U_{b}$ is the wave orbital velocity, $U_{c}$ is the current velocity, $\alpha$ is the angle between wave and current, and $f_{w}$ is the wave friction factor.

\section{RESULTS AND DISCUSSION}

Different soil properties were observed among the samples. Clay content, which is responsible for cohesion, varied between $24 \%$ and $94 \%$. Critical shear stress varied between $0.31 \mathrm{~Pa}$ and $10.25 \mathrm{~Pa}$, while the material dependent coefficient (M) varied between 0.325 and 8.67. The lowest critical shear stress was observed in the area with the lowest cohesion and high silt content (Site 7, Fig. 1). The highest material dependent coefficient (M) was observed in sample 8 Mile (2-2) at site 2 where the sample contained a high amount of clay but many cracks and fissures were observed through the sample due to severe freezing and thawing (Fig. 5). The summary of experimental results and soil properties are presented in Table 1. The 8-Mile channel banks contained different soil type properties: sites 1,2 and 3 had high clay content, site 4 had high sand content soil, sites 5 and 6 contained mainly peat material, and site 7 contained a high amount of silt. The 2-Mile channel banks mainly contained sand and non-cohesive soils but in the middle of the channel at the location of site 2 cohesive banks were observed which contained a high amount of clay. 


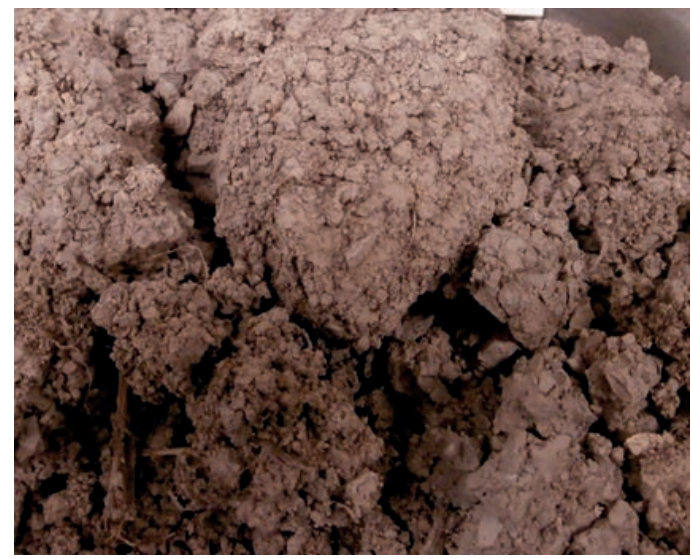

Fig. 5 Sample 8M (2-2) with the highest (M) value.

Table 1 Physical properties of soil samples.

\begin{tabular}{|c|c|c|c|c|c|c|c|c|c|c|c|c|c|c|c|}
\hline ID & $\begin{array}{l}\mathrm{CEC} \\
(\mathrm{meq} / 10 \\
0 \mathrm{~g})\end{array}$ & $\begin{array}{l}\mathrm{EC} \\
(\mathrm{dS} / \mathrm{c} \\
\mathrm{m})\end{array}$ & $\begin{array}{l}\mathrm{OM} \\
(\%)\end{array}$ & SAR & $\begin{array}{l}\mathrm{d}_{50} \\
(\mathrm{~mm})\end{array}$ & $\begin{array}{l}\rho_{\text {dry }} \\
\left(\mathrm{kg} / \mathrm{m}^{3}\right)\end{array}$ & $\begin{array}{l}\mathrm{C} \\
(\mathrm{KN} / \\
\left.\mathrm{m}^{2}\right)\end{array}$ & $\tan \emptyset^{\prime}$ & $\begin{array}{l}\text { Sand } \\
\%\end{array}$ & $\begin{array}{l}\text { Silt } \\
\%\end{array}$ & $\begin{array}{l}\text { Clay } \\
\%\end{array}$ & $\begin{array}{l}\mathrm{W} \\
\%\end{array}$ & PI \% & $\tau_{\mathrm{c}}(\mathrm{Pa})$ & $\begin{array}{l}\text { Slope of } \\
\text { the } \\
\text { erosion } \\
\text { rate }\end{array}$ \\
\hline $2 \mathrm{M}(2-1)$ & 23.6 & 0.446 & 1.1 & 1.071 & 0.002 & 1567 & 8.3 & 0.5511 & 14 & 44 & 42 & 28 & 21 & 7.81 & 0.673 \\
\hline $2 \mathrm{M}(2-2)$ & 23.1 & 0.462 & 1.0 & 1.075 & 0.002 & 1542 & 11 & 0.4348 & 5 & 45 & 50 & 34 & 24 & 10.25 & 0.641 \\
\hline $8 \mathrm{M}(1-1)$ & 29.2 & 0.406 & 1.4 & 1.621 & 0.00035 & 1419 & 8.5 & 0.5506 & 2 & 4 & 94 & 35 & 27 & 4.85 & 0.325 \\
\hline $8 \mathrm{M}(2-1)$ & 28.2 & 0.284 & 1.4 & 1.373 & 0.0011 & 1512 & 10 & 0.5721 & 6 & 34 & 60 & 27 & 17 & 8.57 & 0.898 \\
\hline $8 \mathrm{M}(2-2)$ & 27.1 & 0.288 & 1.9 & 0.28 & 0.0013 & 1445 & 1.7 & 0.7399 & 2 & 33 & 65 & 23 & 14 & 1.62 & 8.674 \\
\hline $8 \mathrm{M}(3-1)$ & 28.1 & 0.314 & 2.8 & 0.639 & 0.0015 & 1378 & 2 & 0.7378 & 17 & 27 & 56 & 40 & 24 & 2.68 & 0.98 \\
\hline $8 \mathrm{M}(3-2)$ & 24.7 & 0.386 & 2.1 & 1.035 & 0.0017 & 1605 & 2.9 & 0.7497 & 1 & 45 & 54 & 38 & 18 & 2.74 & 0.42 \\
\hline $8 \mathrm{M}(4-1)$ & 22.3 & 0.428 & 1.5 & 0.398 & 0.45 & & & & 75 & 8 & 17 & 27 & \multirow{2}{*}{\multicolumn{3}{|c|}{$\begin{array}{l}\text { Non cohesive behavior } \\
\text { Non cohesive behavior }\end{array}$}} \\
\hline $8 \mathrm{M}(4-2)$ & 19.8 & 0.234 & 0.7 & 0.25 & 0.17 & & & & 71 & 9 & 20 & 22 & & & \\
\hline $8 \mathrm{M}(6-1)$ & 21.6 & 0.204 & 1.2 & 0.239 & 0.02 & 1843 & 2.4 & 0.8965 & 39 & 37 & 24 & 17 & 13 & 1.6 & 6.95 \\
\hline $8 \mathrm{M}(7-1)$ & 26.3 & 0.206 & 1.0 & 0.358 & 0.0074 & 1747 & 1 & 0.869 & 25 & 50 & 25 & 22 & 5 & 0.31 & 3.683 \\
\hline
\end{tabular}

Figures 6 and 7 show the results of the MIKE 21 NSW model simulations for 8-Mile and 2- Mile channels for the maximum flow event. The outputs were used for hydrodynamic modelling of the channels using MIKE 21 FM MT module. For comparison between current induced erosion and wave-current induced erosion, two different models were developed for pure current and also for combinations of wave and current for both sites. Figures 8 and 9 show shear stresses due to a combination of waves and currents.

The results indicate that waves had no significant effects on the applied shear stresses in 8-Mile channel. Figure 8(a) shows that shear stress varied between $0.15 \mathrm{~Pa}$ and $1.80 \mathrm{~Pa}$ under pure current conditions in the high flow seasons and Fig. 8(b) shows that shear stress varied between 0.08 and $1.80 \mathrm{~Pa}$ under a combination of waves and currents. Sites 4, 6, 7, 8 are susceptible to fluvial erosion due to the low critical shear stress. The 2-Mile channel analysis showed that waves had significant effects on the total applied shear stresses at this site and may increase the magnitude of applied shear stresses by up to $180 \%$. Figure 9(a) shows that applied shear stress varied between 0.04 and $0.44 \mathrm{~Pa}$ under pure current conditions, and Fig. 9(b) shows that shear stress varied between 0.04 and $1.25 \mathrm{~Pa}$ under a combination of wave and current. Site 2 in 2-Mile channel (Fig. 1) contained highly cohesive soil with high critical shear stresses ( $>7 \mathrm{~Pa}$ ) but sites 1 and 3 contained fine sands where erosion can occur although the magnitude of shear stresses during high flow events were not significant. 
$[-]$

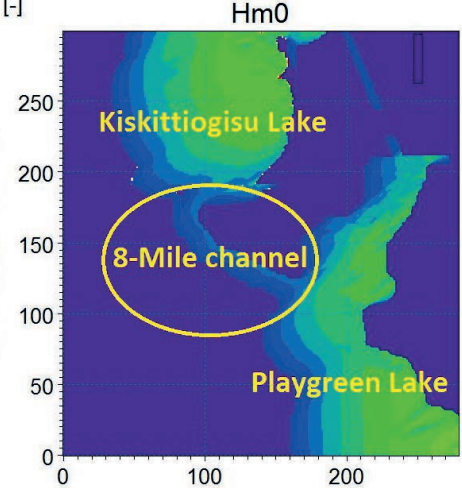

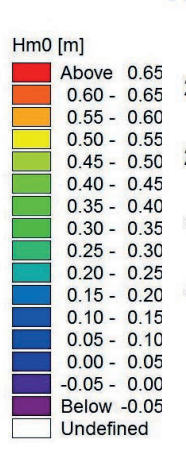

[-] $\quad T m$

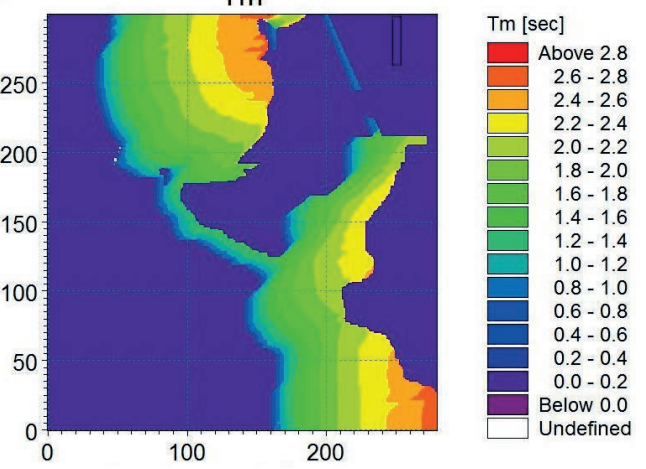

Fig. 6 Significant wave height and wave period in 8-Mile channel (MIKE 21 NSW).
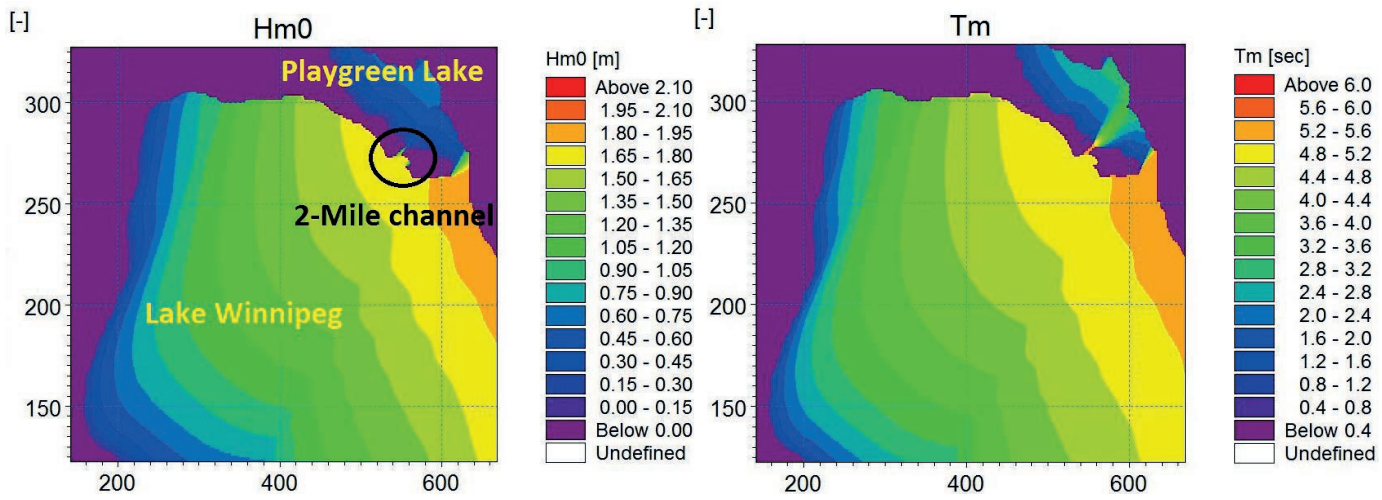

Fig. 7 Significant wave height and wave period in 2-Mile channel (MIKE 21 NSW).

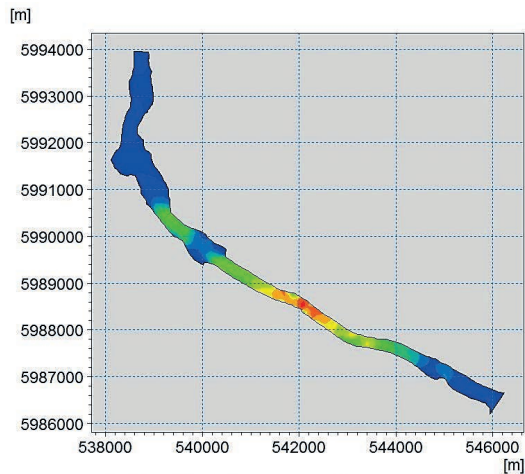

(a)

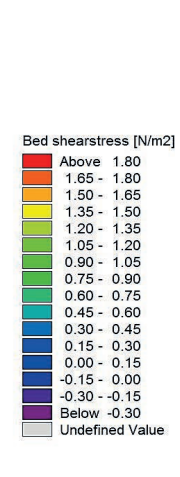

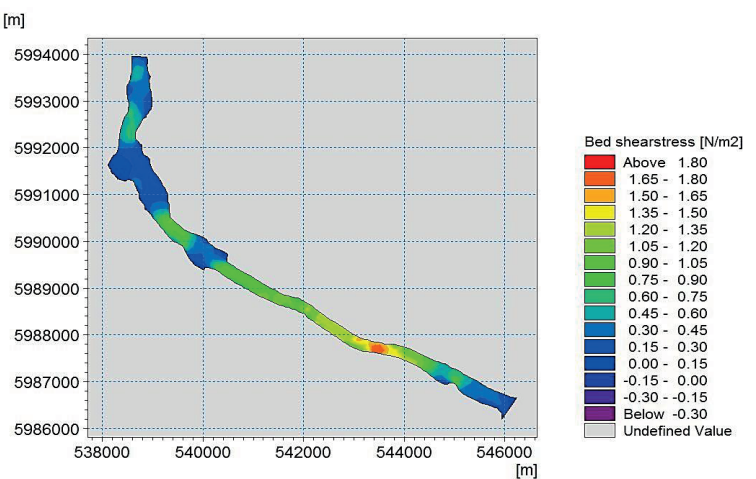

(b)

Fig. 8 Max event shear stresses in the 8-Mile channel due: (a) to currents, (b) to a combination of current and waves.

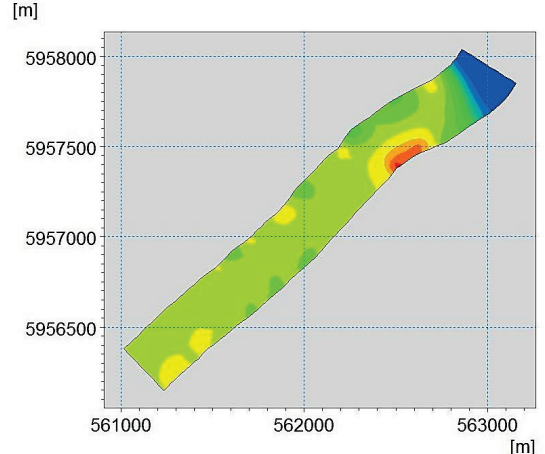

(a)

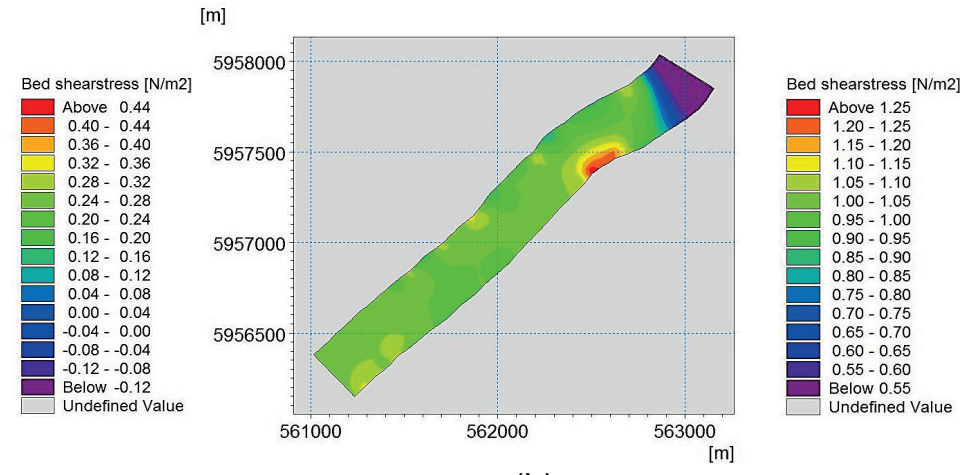

(b)

Fig. 9 Max event shear stresses in the 2-Mile channel due: (a) to currents (b) to a combination of current and waves. 


\section{CONCLUSION}

Two channels connecting lakes in northern Manitoba were investigated for bank erosion, where the effects of waves and currents were considered. Several soil properties were measured to understand the behaviour of cohesive soil erosion. Results showed that waves can be a dominant eroding agent in rivers and channels, therefore wave monitoring and flow measurements during the high flow seasons are crucial. Waves had a significant effect on the total applied shear stress in 2-Mile channel but were insignificant in 8-Mile channel. Results from the soil properties analysis indicated that a strong correlation was observed between the cohesion obtained from direct shear test and critical shear stress. Additionally, results suggested that erosion rate is a function of flow and wave condition, in situ mechanical soil properties, and sodium adsorption ratio. More details on the effects of each variable on cohesive soil erodibility are discussed by the authors in a separate paper currently under review. To facilitate accurate estimation of the total applied shear stresses in channels and rivers, especially navigation and lake regulation channels, periodic wave measurements are necessary since wave boundary conditions significantly affect the predicted wave parameters and the total applied shear stresses.

Acknowledgements This research was supported by Manitoba Hydro and the Natural Sciences and Engineering Research Council of Canada. The authors would like to thank Nathan Lambkin and his team from Manitoba Hydro for their help and contributions during field measurements and also Kerry Lynch, manager of the geotechnical lab at the University of Manitoba, for his help with the experiments.

\section{REFERENCES}

Briaud, J.L., et al. (2001) Erosion function apparatus for scour rate predictions. Journal of Geotechnical and Geoenvironmental Engineering 127(2), 105-113.

DHI (2012) MIKE 21 FM Scientific Documentation. DHI Company, Horsholm, Denmark.

Farhadzadeh, A., Kobayashi, N. \& Gravens, B. (2012) Effect of breaking waves and external current on longshore sediment transport. Journal of Waterway, Port, Coastal, and Ocean Engineering, ASCE 138, 256-260.

Gaskin, S.J., Pieterse, J. \& Lepage, S. (2003) Erosion of undisturbed clay samples from the banks of the St. Lawrence River. Canadian Journal of Civil Engineering 30, 585-595.

Gourlay, T. (2010) Full-scale boat wake and wind wave trials on the Swan River. Centre for Marine Science and Technology, Curtin University research report No: 2010-06.

Gourlay, T. (2011) Notes on shoreline erosion due to boat wakes and wind waves. Centre for Marine Science and Technology, Curtin University research report No: 2011-16.

Holthuijsen, L.H., Booij, N. \& Herbers, T.H.C. (1989) A prediction model for stationary, short-crested waves in shallow water with ambient currents., Coastal Engineering 13, 23-54.

Kimiaghalam, N., et al. (2013) Riverbank erosion on the Red River in Winnipeg. 21st Canadian Hydrotechnical Conference (CSCE), Alberta, Canada, paper: CSCE-64.

Partheniades E. (1965) Erosion and deposition of cohesive soils. Journal of Hydraulics Engineering ASCE 91(1), 105-138. 